$\underline{\text { Review Article }}$

\title{
DETAILED VIEW ON REPURPOSED DRUGS, TRACKING OF VACCINES,AND BRIEF VIEW ON PROPHYLACTIC NANOMEDICINES AS AN ALTERNATIVE APPROACH AND PATIENT CARE FOR COVID-19
}

\author{
KRISHNANJANA S. NAIR ${ }^{1}$, SHIVALI KAMATH ${ }^{1}$, ARYA RAJAN ${ }^{1}$, SACHIN THOMAS ${ }^{1}$, ASWIN D. ${ }^{1}$, SUBIN MARY \\ ZACHARIAH* $^{*}$
}

1Department ofPharmaceutical Chemistry and Analysis, Amrita School of Pharmacy, Amrita VishwaVidyapeetham, AIMS Health SciencesCampus, Kochi 682041,Kerala, India

Email: subinzac@gmail.com

Received: 20 Sep 2020, Revised and Accepted: 200 ct 2020

\begin{abstract}
In December 2019, a rare case of pneumonia was reported in Wuhan, China. This was later analyzed and known to have similar characteristics as viral pneumonia caused by a novel coronavirus. Later, on 11 February 2020, the World Health Organization (WHO) officially named the disease as COVID19. The Severe acute respiratory syndrome coronavirus 2(SARS-CoV-2) ought to taint both the upper respiratory tract and the lower respiratory tract. This COVID-19 is spreading quickly with an immense rise in cases around the world. This infection's mechanism stays obscure, and the medications explicit for the infection were not grown at this point. Infection is highly contagious. Severe Acute Respiratory Syndrome Coronavirus 2(SARS-CoV-2) is one of seven kinds of crown infection, including the one which causes severe maladies like Middle East respiratory disorder (MERS) and abrupt, intense respiratory syndrome(SARS). Since its revelation, the infection has spread and has caused anxiety and fear among people. Recent vaccines are tracked, and clinical trials can bring an immediate protocol on a medication approach. By including different therapeutic approaches, it is easier to combat the disease quickly. With very low mortality and high transmission rate, new approaches to vaccines and nanomedicines bring down the spread. Controlled patient care is also crucial. On 11 March, the World Health Organization (WHO) declared the disease as 'global pandemic'. COVID-19, therefore, poses a significant threat to global public health.
\end{abstract}

This article reviews the epidemiology, pathogenesis, and diagnostic methods. The review also focuses on repurposed drugs, traced vaccines, and a quick view of prophylactic nanomedicines as an alternative for COVID 19. For this review, the complete database has been collected from various search engines such as PubMed, ScienceDirect, Scopus, Elsevier, etc., from the year 2001-2020 using the following keywords.

Keywords: SARS-CoV-2, Covid-19, Infectious disease, Serology, Vaccine, Repurposing/repositioning drugs, Global pandemic, Cytokine storm, Pneumonia, Lung injury

(C) 2021 The Authors. Published by Innovare Academic Sciences Pvt Ltd. This is an open access article under the CC BY license (http://creativecommons.org/licenses/by/4.0/) DOI: http://dx.doi.org/10.22159/ijap.2021v13i1.39705. Journal homepage: https://innovareacademics.in/journals/index.php/ijap

Speedy peer review was done as the subject of the manuscript was related with pandemic.

\section{INTRODUCTION}

COVID-19 is a world pandemic that affects human life and our livelihood [1]. Novel virus-induced coronavirus disease (COVID-19) was an outbreak that started in Wuhan, China [2]. However, the Severe Acute Respiratory Syndrome Coronavirus 2 (SARS-CoV-2) virus causes respiratory problems; however, this virus can spread through the air. The family of this virus can cause breathing illnesses in humans, in the form of common cold or pneumonia in addition to breathing infections [3-5]. The outbreak hastily grew and spread to the neighboring countries. Necessary action has been taken by the Ministry of Health and Family Welfare of India and raised awareness of the pandemic and managed the spread of COVID-19. The central and state governments have taken several measures and formulated several protocols to achieve their desired goal. India has not thrown off the pandemic, where it also gets dangerous. Medically adequate studies have been undertaken to solve this trouble worldwide [6]. Researchers are working day and night to acquire the vaccination for this single-stranded RNA, including viruses [7]. The present research has initiated people looking ahead to the prominent answers to clear up this pandemic threat. Perhaps, medical experts and wealthier people can assume vaccination. Prevent contagious spread and protect themselves by washing hands while coughing and sneezing, covering mouth and nose, and eating well-cooked meat and eggs. Reduce contact with people with respiratory symptoms.

\section{Epidemiology}

On 31 December 2019, the World Health Organization(WHO) Country Office in China reported pneumonia cases with unknown (causes) aetiology in Wuhan, Hubei Province, China. From 31
December 2019 to 3 January 2020, the Chinese national authorities informed the World Health Organization of 44 cases of pneumonia with aetiology being unknown. No cause was found for the occurrence of these cases of pneumonia during this reporting period. On 11 and 12 January 2020, the World Health Organization(WHO) received information from the National Health Commission China that exposure to a seafood market in Wuhan was associated with the spread. The Chinese authorities identified a new corona-virus causing pneumonia and isolated it on 7 January 2020. Furthermore, on 12 January 2020, China publicized the genetic sequence/Genomic analysis data to other countries to engineer specific diagnostic kits. 213 Countries and Territories around the world have reported confirmed cases of the corona-virus COVID-19 [8].

\section{Transmission}

Respiratory infections can be spread through droplets. According to the evidence collected, the COVID-19 virus was transferred through droplets from the respiratory tract and interaction with people [9]. So it is essential to use personal safety events such as using masks and keep up social separation are some events taken to control the infection from an infected individual to non-infected individuals [10]. Respiratory droplet transmission occurs in case of close contact with people within 1 metre, with someone having respiratory symptoms like cold, coughing, sneezing, and they are at high risk of exposing their eyes, mouth, nose to infected respiratory droplets[11]. Transmission can occur by direct contact with an infected person or by indirect contact with the infected person's environment and substances [12]. Air bone spread is different from that of droplet spread as it refers to microbes in the droplet nuclei that can remain in the air for an extended time and can transmit within a distance of 1 meter [13]. 


\section{Clinical features}

Covid19 manifestations can range from asymptomatic to severe septic shocks and multiorgan dysfunction. COVID-19 is classified based on the disease's severity from less severe symptoms to the most severe symptoms. The most common symptoms of patients include fever (98.6\%), fatigue (69.6\%), dry cough, and diarrhoea. For each individual, the effect of COVID-19 is different [14]. Most infected individuals show symptoms which can be cured without getting into hospitals.

The most common symptoms include-fever, acne, dry cough, fatigue, diarrhoea, nausea, and sore throat.

Less common symptoms include-discoloration of the skin, rashes on fingers, loss of taste or smell, pain, and headaches.

Severe symptoms include-breathing difficulty, shortness of breath, pain, or pressure on the chest, loss of movement. Usually, it takes an average of $14 d$ to show symptoms, and usually 5-6 d to get infected [15].

\section{Diagnosis}

COVID 19 diagnosis is vital and essential. Due to the extreme spike in more than 100 countries, identifying infected persons with Severe Acute Respiratory Syndrome Coronavirus 2(SARS-CoV-2) helps guide those individuals in terms of treatment and indicates who needs to be isolated. They have their contacts traced and identified. This prevents the further spread of the disease and promotes effective infection control. Even if a vaccine is developed, diagnostic testing is critical to ensure that the vaccine is used as effectively and efficiently as possible. It also indicates those who are at high risk of coronavirus and those infected who are fully recovered.

Diagnostic tests depend on viral load in the upper and lower respiratory tract.

Two major tests are

1. Viral test.

\section{Serological test.}

Other tests include Computed Tomography(CT) scan, Magnetic Resonance Imaging(MRI) scan, or checking body temperature or checking low oxygen levels.

Tests are done to check for current infection and the possibility of past infection.

\section{Viral load test}

This test is done to check if the patient has a current infection

Early screening or diagnosis of infection is often recommended before the 6th day of developing symptoms. Here a nasopharyngeal swab or an or pharyngeal swab is taken as a specimen. These specimens contain high viral loads. Swabs should be kept in place for 10 s while being twirled three times. To the nasal cavity, the swab is inserted deeply [16, 17].

Laboratory analysis thereby takes 1-2 d after specimen collection. Rectal swabs can also be used to detect the Severe Acute Respiratory Syndrome Coronavirus 2(SARS-CoV-2) in stool and their recurrent shedding. This helps in monitoring of patients in terms of infectivity and cure [18]. Positive results are accurate, but there is a high chance of negative results, which does not rule out infection. If the viral test is negative, it does not mean a person was not infected with the virus but infected at an early period and may not show any signs of infection during the time of testing. In such cases, an antibody test is done, which indicates past infection.

\section{Serology test}

Antibodies are disease-specific, and this test helps detect antibodies corresponding to virus antigens present in the blood. Various serology tests are specific, and the antibodies are detectable only after 10-14 d after the infection (mainly the presence of Immunoglobulin $\mathrm{G}$ antibodies(IgG)). The average peak is $28 \mathrm{~d}$ after the initial onset [19]. Serological methods are mainly used to find out $\mathrm{S}$ protein, which is an antibody against coronavirus. This spike determines host tropism and transmission capability. Immunoglobulin M(IgM)and Immunoglobulin G(IgG)are the two primary antibodies produced against the antigens in response to infection. Results produced if positive, then treatment should be initiated immediately, and persons must be careful without spreading the disease. There is also a chance of having viruses of the same family as that of coronaviruses. If the test results are negative, then the person may not have developed any antibodies but can have infection and chances of developing antibodies in later stages. In 30 percent of cases, there is a chance of antibodies on the $7^{\text {th }}$ day of the infection [20].

\section{Pathogenesis}

Pathology varies among adults and children. Infectivity of Severe Acute Respiratory Syndrome Coronavirus 2(SARS-CoV2) is much higher than Severe Acute Respiratory Syndrome Coronavirus 1(SARS-CoV1) [21]. As per clinical, immunological progression, the disease progresses in 3 different phases that include a flu-like phase with high viral load, a critical phase which includes viral response (lung and lung injury), and the recovery phase. In elderly persons, cytokine expression is highly increased and is followed by consecutive overactivity of innate immunity followed by virusinduced cell injury. Various Immune mechanisms include trained immunity, cross-immunity to coronavirus infection, developmental changes in immunity, and repair of inflammatory lung damage are some protective mechanisms involved.

COVID-19 disease is caused by the pathogen beta-coronavirus, whichbelongs to the genera of the coronaviridae family. Pathogenesis is similar to Severe Acute Respiratory Syndrome Coronavirus 1 (SARS-CoV1) and the Middle East Respiratory Syndrome Coronavirus(MERS-CoV), respectively [22]. Severe Acute Respiratory Syndrome Coronavirus 2(SARS-CoV-2) consists of an envelope with a positive-sense single-stranded RNA virus from the beta coronavirus. The surface spike proteins give a crown-shaped structure on electron microscopy. Alpha and beta coronaviruses mainly affect mammals among the four different genres, such as the alpha, beta, gamma, and delta coronavirus [23].

Coronavirus mainly consists of 4 parts, the spike, envelope, membrane, and nucleocapsid [24]. Spikes defines the host tropism. Spike comprises two main subunits S1 and S2. S1 subunit binds to the host cell receptor while the S2 subunit fuses to viral and cellular membranes. Angiotensin-Converting Enzyme 2 (ACE2) is the primary functional receptor for Severe Acute Respiratory Syndrome Coronavirus (SARS-CoV). Angiotensin-Converting Enzyme 2 (ACE2) receptors are mainly present in the lungs, heart, kidneys, ileum, and bladder [25]. Virus entry is through proteolytic cleavage at the Angiotensin Converting Enzyme (ACE) receptor binding site mainly by transmembrane serine protease 2 . Once the virus enters through the nasal cavity or the oral route to the epithelial cells of the nasal cavity and starts replicating. This state is called an asymptomatic state where the viral load is very low and is the initial infection phase. Furthermore, the virus can be detected by nasal swabs [26].

Once spike protein binds to the host protein, it undergoes protease cleavage and activates spike proteins. Entry is by direct membrane fusion. Cleavage mainly occurs at the S2 site [27].

The virus then propagates to the lower respiratory tract, and an innate immune response is triggered. Immune response mainly includes C-X-C Motif Chemokine Ligand 10 (CXCL10) beta and lambda interferon's, which act as disease markers in SARS. Antigen presentation is followed by subsequent stimulation of humoral and cellular immune responses, which is later mediated by virus-specific $B$ cells and T cells [28]. Most of the infected patients are affected at the upper respiratory tract, and patients are monitored at home, giving symptomatic therapy. Lymphopenia is a clinical presentation at the initial stages.

\section{On the progression of the disease}

Disease progression is characterized by pulmonary infiltrates and is mainly seen in aged persons at high risk. The virus then reaches the 
lungs' gas exchange units, affecting alveolar type 1 and type 2 epithelial cells [29]. A large number of virus particles are released, and the cell undergoes apoptosis. Self-replicating pulmonary toxins are released subsequently. The patient then shows symptoms of acute respiratory distress syndrome (ARDS). The process is then followed by a cytokine storm which includes a spike in an uncontrolled systemic inflammatory response which involves the deadly release of pro-inflammatory cytokines that provides for interferons (IFN) such as (IFN- $\alpha$, IFN- $\gamma$, IL-1 $1 \beta$, IL-6, IL-12, IL-18, IL33 , TNF- $\alpha$, TGF $\beta$ ) and chemokines (CCL2, CCL3, CCL5, CXCL8, CXCL9, CXCL10) immune effector cells in Severe Acute Respiratory Syndrome Coronavirus (SARS-CoV) infection.In patients with severe disease, pathogenic CD4+T cells with co-expressing interferon (IFN)$\gamma$ and granulocyte-macrophage colony-stimulating factor (GM-CSF) were seen in COVID-19 patients. Granulocyte-Macrophage ColonyStimulating Factor (GM-CSF) can initiate tissue damage to high levels [30]. Many inflammatory cells were also seen on lung surfaces of severely infected patients, followed by scarring and fibrosis. Angiotensin-Converting Enzyme 2 (ACE2) receptors are significantly expressed on innate immune cells that are Group 2 and Group 3 Innate Lymphoid Cells (ILC2and ILC3). Multiple organ failure and finally, death results in severely ill COVID 19 infection patients [31].

\section{Therapeutic management approach}

Therapeutic management using repurposing or repositioning of drugs.

\section{Repurposing/repositioning of drugs}

Severe Acute Respiratory Syndrome Coronavirus 2 (SARS-CoV 2) is a novel virus disease, it is tough to get new medicines and vaccines quickly, and the condition worsens. Knowing the pathophysiology very similar to Severe Acute Respiratory Syndrome Coronavirus 1(SARS-CoV-1)and the Middle East Respiratory Syndrome Coronavirus(MERS), getting new medicines having exact drug targets is very difficult and needs many studies and research. Hence, for an immediate cure, knowing about each of these drugs' mechanisms of action makes it easier for immediate therapy but not recommended every time due to its high toxicity. Some countries are against using these drugs, but some use them after many clinical studies. The Discovery of new medicines and their preclinical to phase 3 trials are often time-consuming and require many procedures. Hence, using these repositioned medicines is an effective strategy in managing therapeutic approaches and minimizing its toxicity[32]. These drugs have often been known to humans for past years, need just quick evaluation, and are readily available. Safe vaccination is highly recommended for this infection but not available soon in the COVID 19 outbreak. The virus also undergoes mutations as it progresses; hence, it is difficult to find new drug targets. Therefore repurposing drugs has made the therapeutic approach much more manageable, and the management of the disease is done appropriately without delay. There are many medications used now for repurposing, as shown in table 1.

Table 1: Classification of drugs based on their class

\begin{tabular}{lll}
\hline Drugs & Class & Reference \\
\hline 1. Chloroquine and Hydroxychloroquine & Antimalarial Drugs & [33] \\
2. Lopinavir and Ritonavir & Antiviral Drugs-Protease Inhibitor & \\
3. Nafamostat and Camostat & Protease Inhibitor-Protease Inhibitor & \\
4. Umifenovir & Antiviral Drugs & \\
5. Nitazoxanide & Antiprotozoal & \\
6. Ivermectin & Anthelmintics & \\
7. Corticosteroids & Steroid Hormone \\
8. Tocilizumab and Sarilumab & Interleukin-6 Blockers \\
9. Bevacizumab & Antiangiogenic Agents \\
\hline
\end{tabular}

\section{Repurposed drugs}

\section{Chloroquine and hydroxychloroquine}

Drugs for COVID 19 virus for repurposing are divided into two categories: the one targeting the replication cycle and one that controls the disease's symptoms. The polymerase inhibitor aminoquinolinesChloroquine (CQ) and Hydroxychloroquine(HCQ) are used as antimalarial therapy. There is an accumulation of toxic heme in parasites because the antimalarial drugs inhibit heme polymerase, leading to death. In the case of COVID-19, drugs will keep the virus away from the host cell by lysis of the host receptor's glycosylation and break down viral protein production by inhibiting endosomal acidification in vitro [34]. The benefit is attributed to the well-known lysosomotropic property of the drug and Interferes with ACE2 receptor glycosylation and the autophagic process, thereby blocking the viral attachment and entry. The first documented report was from China; Hydroxychloroquine(HCQ) was more potent and safer than Chloroquine(CQ), which was the concluding statement. Hydroxychloroquine(HCQ) was more potent than Chloroquine(CQ) to inhibit Severe Acute Respiratory Syndrome Coronavirus 2 (SARS-CoV-2), and the combination of Hydroxychloroquine(HCQ) with Azithromycin in patients with COVID-19 led to a decline in COVID-19 mortality [35]. Chloroquine (CQ) showed remarkable results both in terms of clinical outcome and viral clearance compared with the control group. Treatment, in combination with Azithromycin, appeared to induce conduction disorders and increased Cardiovascular(CV) mortality.

Chinese researchers found that chloroquine is highly useful and effective in reducing the viral replication that can be achieved by standard dosing due to its penetration into tissues, including the lungs [36]. The only difference between chloroquine and hydroxychloroquine is the hydroxyl group at the terminal. Both are weak bases, leading to a change in the PH of intracellular organelles that is acidic and is vital for the fusion of membranes. It is learned that antiviral and anti-inflammatory action is essential in the COVID 19 treatment [37]. Chloroquine(CQ) and Hydroxychloroquine(HCQ) have been used to reduce symptoms duration, exacerbation of pneumonia. So this led to including chloroquine and hydroxychloroquine in prevention and treatment [38]. A trial for Hydroxychloroquine(HCQ) was conducted in France and it was found that Hydroxychloroquine(HCQ) when used alone or in combination with Azithromycin was effective in clearing viral nasopharyngeal carriage. (Measured by Polymerase Chain Reaction (PCR)).This shows the synergistic effect of Azithromycin with Hydroxychloroquine(HCQ) [39]. While using these drugs, some precautions must be taken, monitoring hematological parameters (Red Blood Cell(RBC), White Blood Cell(WBC), and platelet counts), serum electrolytes measurement, blood glucose, hepatic, and renal function [40]. The World Health Organization (WHO) removed the above drugs by accepting solidarity trial recommendations formulated by the Solidarity trial interim committee. However, Solidarity clinical trials were not done in pre and post-exposure patients, hence it could be beneficial for pre and post-exposure prophylaxis.

\section{Lopinavir and ritonavir}

Lopinavir and Ritonavir are new classes of drugs that work by inhibition of 3 chymotrypsin-like proteases and papain-like proteases, and it comes under the protease inhibitor category.

For the infection of the virus, no therapeutic agents are known. However, as these proteases cleave at various polypeptides, thereby producing individual functional proteins such as RNA-dependent 
RNA polymerase(RdRPs) andNon-Structural Proteins(NSPs), this process is also inhibited, blocking the replication process [41]. Lopinavir is a protease inhibitor that acts by inhibiting the viral target molecules [42]. By inhibiting cytochrome p450 enzyme, it can increase the plasma half-life of the drug and is usually done by a combination of Ritonavir and Lopinavir. A combination has also improved efficiency.

A study done in 2004 shows a decrease in acute respiratory distress syndrome by combining ribavirin with Lopinavir-Ritonavir and reducing death [43].

Some random clinical trials show that drugs given in combination are more effective than standard care because the drug's side effects have limited appeal. Significant side effects include liver damage, nausea, and diarrhoea [44]. There is also a risk of QT prolongation and cutaneous reactions. According to the National Institute of Health's(NIH) updated information, a randomized, double-blind, placebo-controlled clinical trial was conducted on 4000 participants. It was a Multi-centric, Phase 2-like, investigator-directed trial, where hospitalized adult patients with laboratory-confirmed Severe Acute Respiratory Syndrome Coronavirus 2 (SARS-CoV-2) infection provided information based on the trial and offered enrollment[45]. The World Health Organization(WHO) in July discontinued the use of the above drugs by accepting recommendations from the Solidarity Trial's International Steering Committee.

\section{Nafamostat and camostat}

Nafamostat and camostat were used for pancreatitis in japan, which comes under serine protease inhibitors. Previously camostat acted as an antagonist to serine protease to block the entry of Severe Acute Respiratory Syndrome Coronavirus (SARS-CoV), and it is said that camostat and nafamostat have a similar action in inhibiting Severe Acute Respiratory Syndrome Coronavirus (SARS-CoV).

Its primary target molecule is Transmembrane Protease Serine 2(TMPRSS2). According to the reports obtained from an experimental study in Japan for efficient fusion of Severe Acute Respiratory Syndrome Coronavirus (SARS-CoV 2) into the infected human cell, both the receptors' expression is required. Results also reported that Nafamostat was tenfold more potent than Camostatmesylate and had themost significant activity compared to camostatmesylate. Later studies also reported that nafamostat has higher efficiency in inhibiting the viral cell entry, almost 15 folds higher than camostat. Namostat and Camostat have undergone various clinical trials for COVID 19 in the United States of America (USA) and Japan [46].

\section{Umifenovir}

Central Drug Research Institute (CDRI), a lab in India-primarily based Council of Scientific and Industrial Research (CSIR), has got approval for using Umifenovir for the Phase III trial. In this randomized, double-blind, placebo-controlled trial, Central Drug Research Institute(CDRI) will test the efficacy, protection, and tolerability of Umifenovir.

According to the statement by the government: "This drug has a good protection profile and acts through stopping access of viruses into human cells and also with the aid of priming the immune system."

Umifenovir, a drug used to treat influenza, was readily available in China and Russia, and this drug can also be used for treating COVID-19 patients. CSIR-CDRI is conducting this trial to examine its efficacy in Indian patients. CSIR-CDRI has evolved the manner generation for Umifenovir[47]. Umifenovir was first used in Russia and China to treat influenza viruses A and B. The drug comes under the category of indole-derivative. By the assessment of lopinavir/ritonavir, it was said to be effective against the virus. A new trial observed treatment to be less potent for people with mild COVID-19.

\section{Nitazoxanide}

Nitazoxanide, an anti-parasite drug used to treat cryptosporidiosis and giardiasis, each parasite causes diarrhoea and some anaerobic bacteria, viruses, and different protozoa. It is rapidly metabolite
Nitazoxanide, which has not been examined for its interest against Severe Acute Respiratory Syndrome Coronavirus 2(SARS-CoV-2) as yet. However, it does show in vitro activity, like nitazoxanide, against the influenza virus and another coronavirus, rotaviruses, and the hepatitis $\mathrm{B}$ and $\mathrm{C}$ viruses. It may reduce the symptoms and shedding of SARS-CoV-2, and improve the innate immune responses, increasing interferon type 1 production. It additionally blocks TMEM16A ion channels and so causes bronchodilation. It is relatively safe, with minimum unfavorable gastrointestinal effects when given as a single oral dose at up to 4 grams.It is advocated to be taken after food, as this will increase the plasma levels.

An ongoing clinical trial is anticipated to provide records on the interest of Nitazoxanide at a dose of $500 \mathrm{mg}$ twice daily(BD), either alone or at the side of Hydroxychloroquine(HCQ), in opposition to SARS-CoV-2. However, there is no publicly available assisting evidence for this dose against the virus [48]

\section{Ivermectin}

Ivermectin is a drug that can treat many diseases because of its antimicrobial, antiviral, and cancers. It is enormously influential towards many microorganisms which have some viruses. Different studies on ivermectin show its antiviral effects on RNA viruses, which carries with it Zika, dengue, infectious disease, and severe acute respiratory syndrome coronavirus 2 [46].Ivermectin acts as a character in various organic mechanisms, consequently being inclusive of COVID-19 as different kinds of high-quality on singlestranded RNA viruses [49].

Ivermectin is used as an antiparasitic drug that may influence invertebrates and is typically a lipophilic macrolide. Ivermectin acts by binding to glutamate-gated chloride ion channels in parasites, leading to paralysis or loss of life of the parasite. It is assumed to bind and destabilize Severe Acute Respiratory Syndrome Coronavirus(SARS-CoV) cells and transport proteins that enter the nucleus. In an observational study, the administration of ivermectin will lead to a low death rate. With a minimum of trials are presently recruiting members to check the efficacy of the drug [50].

\section{Corticosteroids}

Researchers are trying to reduce the potential cytokines storm that leads to respiratory injury and acute respiratory distress syndrome in people. In conjunction with effectiveness, one of the main concerns is the safety of these medications. Also, this drug has chances of other infections related to the disease. It is chief among the immunomodulatory drugs. These are well studied but have cases of adverse reactions. Some molecules inhibit gene expression, which codes for inflammatory molecules. Nevertheless, long term use can cause bone density loss. A previous report says corticosteroids provide a risk of higher mortality in those with influenza pneumonia [51].

\section{Tocilizumaband sarilumab}

These are immunomodulatory mediators and are Interleukin-6(IL6)alpha inhibitors commonly used for severe COVID-19 patients. A double-blind placebo-controlled phase 3 clinical trial evaluates the safety and efficacy of Tocilizumab. Tocilizumab could treat about $75 \%$ of patients and out of which most of them required mechanical ventilation, oxygenation, and inflammatory biomarkers. Moreover, the treatment also showed very high survival rates. They are mainly used to reduce the risk of cytokine storm in covid19 infection. Usually used to treat rheumatoid arthritis, Covid-19, it acts in vivoand reduces clinical symptoms of viral infection. It is also an immunosuppressive. Some Chinese studies proved that patients with COVID 19 (15 of 20) treated with Tocilizumab have reduced the use of oxygen supplements and showed that fever reduces rapidly. For 21 patients, another trial was carried out in China using the Interleukin-6(IL-6) receptor antibody, Tocilizumab, which several companies identified to understand the effectiveness against SARSCoV-2. Toxicity includes high toxic erythema and eosinophilia, but no clear cases until now have been founded.

Sarilumab is also another Interleukin-6(IL-6) inhibitor that plays a significantrole in the overactivity of inflammatory response. It is also 
used as an antirheumatic drug. Again it is used for the treatment of severely ill patients. A phase 3 trial was done by US Company Regeneron, Sanofi, in Covid-19 patients. On elevated levels of Interleukin-6(IL-6), repeated doses of either are recommended. Primary toxicities include opportunistic infections and hematologic toxicity, but no cases have been found until now [52].

\section{Bevacizumab}

Bevacizumab is an anti-VEGF recombinant humanized monoclonal antibody, which has been used as an anti-tumour agent. Evidence suggests that Bevacizumab is the best drug for severe and critical
COVID-19 patients. It mainly reduces Vascular Endothelial Growth Factor(VEGF) levels caused by hypoxia, severe inflammation, and increased respiratory tract epithelium, which is infected. This drug might suppress edema in patients with COVID-19.

It is therapeutically useful in Acute Lung Injury (ALI) and Acute Respiratory Distress Syndrome (ARDS) due to increased vascular permeability and induces in pulmonary oedema. The drug is widely used in clinical immunotherapy. In critical COVID-19 patients, it decreases mortality. Common adverse reactions include edema, fatigue, diarrhea, and abdominal pain. It was also used in the treatment of dyspnea symptoms [53].

Table 2: Tracking of some Covid19 vaccines

\begin{tabular}{|c|c|c|c|c|}
\hline Candidate & Vaccine type and characteristics & Trial phases & Institution & Reference \\
\hline 1. AZD1222 & $\begin{array}{l}\text { Chimpanzee adenovirus vector vaccine contains } \\
\text { the gene that codes for SARS-CoV protein. }\end{array}$ & Phase 1 & $\begin{array}{l}\text { The University of Oxford,the Jenner } \\
\text { institute. }\end{array}$ & [54] \\
\hline 2. MRNA-1273 & $\begin{array}{l}\text { RNA Vaccine, lipid nanoparticles contain the } \\
\text { mRNA encoding the SARS-CoV2 S protein. }\end{array}$ & Phase 2 & $\begin{array}{l}\text { Kaiser Permanente Washington } \\
\text { health research institute. }\end{array}$ & \\
\hline 3. BNT162 & $\begin{array}{l}\text { RNA Vaccine-lipid nanoparticles contain the } \\
\text { mRNA encoding the SARS-CoV2 protein. }\end{array}$ & Phase1/2 & Multiple study sites in Europe. & \\
\hline $\begin{array}{l}\text { 4. INACTIVATED D- } \\
\text { VACCINE }\end{array}$ & $\begin{array}{l}\text { Virions inactivated with chemicals or } \\
\text { radiation,without adjuvant, rendering the viral } \\
\text { genome noninfectious. }\end{array}$ & Phase1/2 & $\begin{array}{l}\text { Henan provincial center for disease } \\
\text { control and prevention. }\end{array}$ & \\
\hline 5. BBIBP-CORV & Inactivated virus vaccine. & Phase1/2 & $\begin{array}{l}\text { Henan provincial centre for disease } \\
\text { control and prevention. }\end{array}$ & \\
\hline 6. IND-4800 & $\begin{array}{l}\text { DNA plasmid encoding the SARS-CoV-2 S protein } \\
\text { delivered by electroporation DNA vaccine. }\end{array}$ & Phase 2 & $\begin{array}{l}\text { Centre for Pharmaceutical research, } \\
\text { Kansas city University of } \\
\text { Pennsylvania, Philadelphia. }\end{array}$ & \\
\hline 7. CORONAVAC & Inactivated Vaccine with alum. & Phase 2 & $\begin{array}{l}\text { Sinovac research and developing } \\
\text { Co., Ltd. }\end{array}$ & \\
\hline 8. NVX-COV2373 & $\begin{array}{l}\text { Protein subunit, full length recombinant SARS- } \\
\text { CoV-2 glycoprotein nanoparticle vaccine } \\
\text { adjuvanted with matrixadjuvant. }\end{array}$ & Preclinical & Novavax & \\
\hline
\end{tabular}

\section{Vaccine}

Vaccines are now crucial to prevent the transmission of the disease and to prevent the individuals from infection of Severe Acute Respiratory Syndrome Coronavirus 2(SARS-COV-2). Many vaccines are generated against the SARS-COV-2, for example, DNA and RNA based vaccine, inactivated virus vaccine, viral vector vaccine, recombinant protein vaccine, and live attenuated vaccine. According to the recent update from the World Health Organization(WHO), there are almost 100 vaccines in their development process at various phases, and ten vaccines are under evaluation at the clinical level.

The mRNA type vaccines were given to the infected patients that contain mRNA oligonucleotides that encode antigen of interest. The advantage of this type of vaccine is that it can mimic infection occurring naturally and provide an excellent immune response [55]. The Vaccine Research Center, a unit of the National Institute of Allergy and Infectious Diseases (NIAID) and Moderna,have started developing an mRNA vaccine for COVID 19. Moderna works with the FDA and both government and non-government agencies and is now in phase 2 of development. Other mRNA vaccine makers, such as those by BIONTech and Pfizer, are also under different vaccine development phases [56]. DNA vaccines are more accurate for infectious diseases. Various DNA vaccines use electroporation to bring plasmids and attach adjuvant to improve the immune function. Inovio Pharmaceuticals are developing COVID 19 DNA vaccine to protect from Severe Acute Respiratory Syndrome Coronavirus 2 (SARS-COV-2). It acts by inducing the activation of the $\mathrm{T}$ cell by bringing plasmids that express Severe Acute Respiratory Syndrome Coronavirus 2 (SARS-CoV-2) protein [57]. Viral vector vaccines are mainly present in the host body as its genetic material, leading to infecting the antigen-presenting cells, leading to the induction of both $\mathrm{B}$ cells and $\mathrm{T}$ cells. CanSinoBIO and Beijing Institute of Biotechnology(BBI) develop a viral vector vaccine [58]. Being an inactivated virus vaccine, this type of vaccine works by chemicals such as formalin or heat that maintain the virion structure and preserve its antigenicity and eliminate the potential that causes the infection. Such a type of vaccine was useful and was safe for preventing the poliovirus and influenza virus. Wuhan Institute of Biological Products and The Beijing Institute of Biological Products are developing an inactivated virus vaccine for COVID-19.

Other vaccines developed, such as the live-attenuated vaccine, work by eliminating or reducing the virus's virulence using chemicals. This type of vaccine gives lifelong protection and is not much expensive. Codagenix and the Serum Institute of India developed a live attenuated vaccine against COVID-19. Recombinant protein vaccine has an advantage over other types based on their safety, and side effects are very few, and without introducing the virus, it induces an immune system. The NVX-CoV2373 vaccine developed by Novavax is an example of a recombinant protein-based vaccine [59].

Use of prophylactic nanomedicines as an alternative for Covid-19

Just like other pneumonia-like infections in this case also, the virus mainly targets the lung. Most of the vaccines and medicines that have been brought through repurposing mainly focus on neurological and haematological complications observed during advanced stages of the disease [60].The target of this viral infection is mainly lung and respiratory cells. Biomedical devices thereby help in the easy procurement of compact medicines which are target specific and have improved efficacy and safety [61].It is a simple therapeutic approach and is done by considering the known medicines as lead molecules in which efficacy is enhanced by using other molecules. Lead molecules can interfere in this RNA polymerization using the interference approach, and the dosedependent effect of any molecules can be controlled by exploring conjoining pathways or a combination of molecules. Lead molecules used are generally of those that can quickly be diffused through the nuclear membrane and switch the RNA processes. Viral replication can be thereby controlled using such molecules. Such molecules have similar acid-baseequilibria to that of nucleic acid bases leading to nonspecific inhibition of DNA/RNA polymerization, which even modulates mutation [62]. This then narrows the pathway making it 
specific to organ/tissue/cells as targeting approaches. Metered devices such as inhalers are then used for targeted drug delivery to the lungs. Antimicrobial functions can be induced by self-dividing nanoparticles with catalytically active surfaces engineered with drug carriers that are target specific and involve conjoining the pathways. Prophylactic drugs developed are of two types: the new drug lead and another for reducing the primary lead molecule dose. As explained above, an example of such a mechanism includes using pyridoxine with nicotine, theophylline, and caffeine that reduces the $\mathrm{pH}$, thereby suppressing nucleic acid polymerization; they also modify the dose. Such molecules have specific receptor-mediated activities like competitive inhibition for suppressing viral binding and replication. Therefore, advances in pulmonary medicines should be modified so that they can deliver such medicines in a simplified manner. Moreover, the delivery is done either in a single route or through multiple route administration such that prophylactic concentration is procured. Therefore, this expands the approach of new medicinal applications. These applications are also valid for developing broad-spectrum antivirals for many viral infections other than Covid-19 that can mainly affect the lungs [63].

\section{Steps to be taken by people and patient care}

Protect ourselves and people around us by making aware of the situations and taking needed measures as precautions. Follow all the guidelines given by the Indian health authority.

To stop the transmission of the virus:

To kill the virus present in the hand, wash the hands frequently with soap and water or use an alcohol-based hand rub [64].

Maintain a safe distance from coughing and sneezing people because when they cough or sneeze, sometimes fine droplets are sprayed from the infected person to non-infected ones in which the droplet may contain the virus. If people stand too close to the infected when they breathe, the virus may directly get into the body of the non-infected people.

It is recommended to wear a mask in public because if people come closer to someone having the coronavirus, they can infect the non-infected individual [65].

- Do not touch the eyes, nose, or mouth, which may ake up the virus present in the hands. When the hand is contaminated with the virus, it can directly spread from the eyes, nose, or mouth to the body and cause infection [64].

While coughing or sneezing, take a towel and cover the nose or mouth and dispose of it after use. We can protect people around us by following good respiratory hygiene.

If minor respiratory symptoms are seen, be at home and take rest until recovery.

In case of any respiratory symptoms or fever, ask for medcal help as soon as possible, call them because it helps to get the right and timely health facilities. This will also help to prevent the spreading of the disease to our dear ones.

Calling the medical team in advance can quickly direct the patient to the right health facility. This protectspeople around the infected ones and prevents the spread of the virus and other infections.

Shaking hands and coming in close contact can transmit the virus due to its high transmission rate and avoid close contact.

Sharing personal items like clothing, phones, utensils, and other items can transmit viruses rapidly; hence should be restricted.

Clean and disinfect surfaces like door handles, furniture, toys, and clean commodities like a laptop, phone, etc., which has regular use in a day.

Avoid eating and drinking in publicplaces-the virus can transmit through food utensils, dishes, and cups [65].

Health care workers who care for individuals with infection should try to utilize Personal protective equipment(PPEkits) containing masks, eye protection, gowns, and gloves, which are safety measures that prevent transmission of the virus.
Isolation and contact tracing alone cannot control the spread of disease. Hence people should coordinate accordingly, listen to government officials and healthcare personnel, give them less stress, and tackle the outbreak more efficiently [64].

\section{CONCLUSION}

The novel coronavirus spread so rapidly that it has changed the rhythm of the world. The use of repositioned medicines helps in managing the rapid disease spread. The specificity of drug repositioning drug molecules brings about effective disease management and strategic treatment protocol. However, Chloroquine, Hydroxychloroquine, Lopinavir, and Ritonavir have been discontinued, but existing clinical trials are going on for prophylaxis and early-stage treatment. Nafamostatmesylate and Favipiravir have greater chances due to its peculiarities in inhibition of Severe Acute Respiratory Syndrome Coronavirus 2 (SARS-CoV2). The remaining drugs that include Famotidine, Umifenovir, Nitazoxanide, Tocilizumab, Sarilmumab, and Corticosteroids, have shown better clinical outcomes. However, clinical trials are still ongoing. Also, acceptance of Solidarity clinical trial recommendations is crucial before the release of the drugs.

Vaccine developments are running at various stages, and human trials possess many difficulties and are often time-consuming. Advancement in pulmonary medicine and the development of prophylactics by nanoparticles can improve the management protocol efficiently. As many institutes are involved, many ethical issues arise and can have many conflicting interests. Hence there is hope for these treatment managements to be a breakthrough in current medicine, as supportive therapy is the need. Also, safety measures should be taken care of, and protocols should be followed for immediate relief.

\section{CONFLICT OF INTERESTS}

With this, the authors declare that there is no conflict of interest related to this review article. The authors listed here have no affiliations with or involvement in any organization or entity with any financial interest (such as honoraria; educational grants; participation in speakers' bureaus; membership, employment, consultancies, stock ownership, or other equity interest; and expert testimony or patent-licensing arrangements), or non-financial interest (such as personal or professional relationships, affiliations, knowledge or beliefs) in the subject matter or materials discussed in this manuscript.

\section{ACKNOWLEDGEMENT}

We authors thank Dr. M. Sabitha, Principal, Amrita School of Pharmacy, and Dr.Subin Mary Zachariah, Associate Professor, Department of Pharmaceutical Chemistry and Analysis, Amrita School of Pharmacy, for helping and guiding us in the manuscript.

\section{FUNDING}

There is no funding support.

\section{AUTHORS CONTRIBUTIONS}

All the authors have contributed equally.

\section{CONFLICTS OF INTERESTS}

\section{Declared none}

\section{REFERENCES}

1. Yang CJ, Chen TC, Chen YH. The preventive strategies of community hospitals in the battle of fighting pandemic COVID19 in Taiwan. J MicrobiolImmunol Infect 2020;53:381-3.

2. Wu JT, Leung K, Bushman M, Kishore N, Niehus R, de Salazar $\mathrm{PM}$, et al. Estimating clinical severity of COVID-19 from the transmission dynamics in Wuhan, China. Nat Med 2020;26:506-10.

3. Zhong NS, Zheng BJ, Li YM, Poon LLM, Xie ZH, Chan KH, et al. Epidemiology and cause of severe acute respiratory syndrome (SARS) in guangdong, people's republic of China. Lancet 2003;362:1353-8. 
4. Wang N, Shi X, Jiang L, Zhang S, Wang D, Tong P, et al. Structure of MERS-CoV spike receptor-binding domain complexed with human receptor DPP4.Cell Res2013;23:986-93.

5. Paden C, Yusof M, Al Hammadi Z, Queen K, Tao Y, Eltahir Y, et al. Zoonotic origin and transmission of Middle East respiratory syndrome coronavirus in the UAE. Zoonoses Public Health 2018;65:322-33.

6. Gralinski LE, Menachery VD. Return of the coronavirus: 2019nCoV. Viruses 2020;12:135.

7. Shereen MA, Khan S, Kazmi A, Bashir N, Siddique R. COVID-19 infection: origin, transmission, and characteristics of human coronaviruses.J Adv Res 2020;24:91-8.

8. Yu WB, Tang GD, Zhang L, Corlett RT. Decoding evolution and transmissions of novel pneumonia coronavirus using the whole genomic data.J Zool Res 2020;41:247-57.

9. Perlow RA, Broyde S. Evading the proofreading machinery of replicative DNA polymerase: Induction of mutation by an environmental carcinogen. J MolBiol 2001;309:519-36.

10. Liu J, Liao X, Qian S, Yuan J, Wang F, Liu Y,et al. Community transmission of severe acute respiratory syndrome coronavirus 2, Shenzhen, China. Emerging Infect Dis 2020;26:1320-3.

11. Emanuel Goldman. Exaggerated risk of transmission of COVID19 by fomites. Lancet Infect Dis 2020;20:892-3.

12. Van DN, Bushmaker T, Morris DH, Holbrook MG, Gamble A, Williamson BN, et al. Aerosol and surface stability of SARS-CoV-2 as compared with SARS-CoV-1. N Engl J Med 2020;382:1564-7.

13. Bansal M, Walia MK. Covid 19-an overview on epidemiology, symptoms, prevention, management, treatment, and role of health workers. Int J Appl Pharm 2020;12:36-41.

14. Huang C, Wang Y, Li X, Ren L, Zhao J, Hu Y, et al. Clinical features of patients infected with 2019 novel coronavirus in Wuhan, China. Lancet 2020;395:497-506.

15. Wu Z, McGoogan JM. Characteristics of and important lessons from the coronavirus disease 2019 (COVID-19) outbreak in China: summary of a report of 142 cases from the chinesecenter for disease control and prevention. J Am Med Assoc 2020;323:1239-42.

16. Pan Y, Zhang D, Yang P, Poon LLM, Wang Q. Viral load of SARSCoV-2 in clinical samples. Lancet Infect Dis 2020;20:411-2.

17. Zou L, Ruan F, Huang M, Liang L, Huang H, Hong Z, et al. SARSCoV-2 viral load in upper respiratory specimens of infected patients. N Engl J Med 2020;382:1177-9.

18. Shi X, Gong E, Gao D, Zhang B, Zheng J, Gao Z, et al. Severe acute respiratory syndrome-associated coronavirus is detected in intestinal tissues of fatal cases. Am J Gastroenterol2005;100:169-76.

19. Zhang W, Du RH, Li B, Zheng XS, Yang XL, Hu B, et al. Molecular and serological investigation of $2019-n C o V$ infected patients: implication of multiple shedding routes.Emerging Microbes Infect 2020;9:386-9.

20. To KK,Tsang OT, Leung WS, Tam AR, Wu TC, Lung DC, et al. Temporal profiles of viral load in posterior oropharyngeal saliva samples and serum antibody responses during infection by SARS-CoV-2:an observational cohort study. Lancet Infect Dis 2020;20:565-74.

21. Qiu H, Wu J, Hong L, Luo Y, Song Q, Chen D. Clinical and epidemiological features of 36 children with coronavirus disease 2019 (COVID-19) in Zhejiang, China: an observational cohort study. Lancet Infect Dis 2020;20:689-96.

22. Channappanavar R, Zhao J, Perlman S. T cell-mediated immune response to respiratory coronaviruses. Immunome Res 2014;59:118-28.

23. Rabi FA, Al Zoubi MS, Kasasbeh GA, Salameh DM, Al-Nasser AD. SARS-CoV-2 and Coronavirus disease. Pathogens 2019;9:231.

24. Bosch BJ, van der Zee R, de Haan CA, Rottier PJ. The coronavirus spike protein is a class I virus fusion protein: structural and functional characterization of the fusion core complex. J Virol 2003;77:8801-11.

25. Baby B, Devan AR, Nair B, Nath LR. The impetus of COVID-19 in multiple organ affliction apart from respiratory infection: pathogenesis, diagnostic measures and current treatment strategy. Infect Disord Drug Targets 2020. DOI:10.2174/1871526520999200905115050.
26. Sims AC, Baric RS, Yount B, Burkett SE, Collins PL, Pickles RJ. Severe acute respiratory syndrome coronavirus infection of human ciliated airway epithelia: role of ciliated cells in viral spread in the conducting airways of the lungs. J Virol 2005;79:15511-24

27. Ou X, Liu Y, Lei X, Li P, Mi D, Ren L, et al. Characterization of spike glycoprotein of SARS-CoV-2 on virus entry and its immune cross-reactivity with SARS-CoV. Nat Commun 2020;11:1620.

28. Tang NL, Chan PK, Wong CK, To KF, Wu AL, Sung YM, et al. Early enhanced expression of interferon-inducible protein-10 (CXCL10 ) and other chemokines predicts adverse outcome in severe acute respiratory syndrome. ClinChem 2005;51:2333-40.

29. Mossel EC, Wang J, Jeffers S, Edeen KE, Wang S, Cosgrove GP, et al. SARS-CoV replicates in primary human alveolar type II cell cultures but not in type I-like cells. Virology 2008;372:127-35.

30. Zhou Y, Fu B, Zheng X, Wang D, Zhao C, Qi Y, et al.Pathogenic T cells and inflammatory monocytes incite inflammatory storm in severe COVID-19 patients. NatlSci Rev 2020;7:998-1002.

31. Tan M, Liu $\mathrm{Y}$, Zhou $\mathrm{R}$, Deng $\mathrm{X}$, Li F, Liang $\mathrm{K}$, et al.Immunopathological characteristics of coronavirus disease 2019 cases in Guangzhou, China. Scilmmunol 2020;160:261-8.

32. Babu BM. Drug repurposing and its implication in therapy: an overview. Int J Res Pharm Sci 2020;2:4418-23.

33. Atlay O, Mohammadi E, Lam S, Turkez H, Boren J, Nielsen J, et al.Current status of COVID-19 therapies and drug repositioning applications. iScience 2020;23:101303.

34. Wang M, Cao R, Zhang L, Yang X, Liu J, Xu M,et al.Remdesivir and chloroquine effectively inhibit the recently emerged novel coronavirus (2019-nCoV) in vitro. Cell Res 2020;30:269-71.

35. Shrivastava A. Analytical methods for the determination of hydroxychloroquine in various matrices.Int J Appl Pharm 2020:12:55-61.

36. Gupta R, Ghosh A, Singh AK, Misra A. Clinical considerations for patients with diabetes in times of COVID-19 epidemic. Diabetes MetabSyndr 2020;14:212-2.

37. Colson P, Rolain JM, Lagier JC, Brouqui P, Raoult D. Chloroquine and hydroxychloroquine as available weapons to fight COVID19. Int J Antimicrob Agents 2020;55:105932.

38. Gao J, Tian Z, Yang X. Breakthrough: chloroquine phosphate has shown apparent efficacy in treatment of COVID-19 associated pneumonia in clinical studies. Biosci Trends 2020;14:72-3.

39. Mason JW. Antimicrobials and QT prolongation. J AntimicrobChemother2017;72:1272-4.

40. Touret F, de Lamballerie X. Of chloroquine and COVID19. Antivirl Res 2020;177:104762.

41. Muramatsu T, Takemoto C, Kim YT, Wang H, Nishii W, Terada $\mathrm{T}$, et al.SARS-CoV 3CL protease cleaves its C-terminal autoprocessing site by novel subsitecooperativity.ProcNatlAcadSci 2016;113:12997-300.

42. Ortega JT, Serrano ML,Pujol FH, Rangel HF. Role of changes in SARS-CoV-2 spike protein in the interaction with the human ACE2 receptor: an in silico analysis.ExpClinToxicokinet2020;19:410-7.

43. Chu CM, Cheng VC, Hung IF, Wong MML, Chan KH, Kao RYT, et al. Role of lopinavir/ritonavir in the treatment of SARS: initial virological and clinical findings. Thorax 2004;59:252-6.

44. Cao B, Wang M, Wen D, Wang J, Fan G, Ruan L et al. A Trial of lopinavir-ritonavir in adults hospitalized with severe covid-19. N Engl J Med 2020;382:1787-99.

45. Hoffmann M, KleineWeber H, Schroeder S, Krüger N, Herrler T, Erichsen S, et al. SARS-CoV-2 cell entry depends on ACE2 and TMPRSS2 and is blocked by a clinically proven protease inhibitor. Cell 2020;181:271-80.

46. Sungnak W, Huang N, Becavin C, Berg C, Queen R, Litvinukova $\mathrm{M}$, et al.SARS-CoV-2 entry factors are highly expressed in nasal epithelial cells together with innate immune genes. Nat Med 2020;26:681-7.

47. Smit MR, Ochomo EO, Aljayyoussi G, Kwambai TK, Chen T, Bousema T,et al. Safety and mosquitocidal efficacy of high-dose ivermectin when co-administered with dihydroartemisininpiperaquine in Kenyan adults with uncomplicated malaria (IVERMAL): a randomised, double-blind, placebo-controlled trial. Lancet Infect Dis 2018;18:615-26. 
48. Crump A, Omura S. Ivermectin, wonder drug' from Japan: the human use perspective. Proc Japan AcadSer B PhysBiolSci 2011;87:13-28.

49. Kircik LH, Del Rosso JQ, Layton AM, Schauber J. Over 25 y of clinical experience with ivermectin: an overview of safety for an increasing number of indications. J Drugs Dermatol 2016;15:325-32.

50. Canga AG, Prieto AMS, Liebana MJD, Martinez NF, Vega MS, VieitezJJG. The pharmacokinetics and interactions of ivermectinin humans-a mini-review. AAPS J 2008;10:42-6.

51. Zhang N, Truong Tran AQ, Tancowny B, Harris KE,Schleimer RS. Glucocorticoids enhance or spare innate immunity: Effects in airway epithelium are mediated by CCAAT/enhancerbinding proteins. J Immunol 2007;179:578-89.

52. Guaraldi G, Meschiari M, Lepri AC, Milic J, Tonelli R, Menozzi M, et al.Tocilizumab in patients with severe COVID-19:a retrospective cohort study. Lancet 2020;2:474-8.

53. Wang Y, Fei D, Vandelaan M, Song A. Biological activity of bevacizumab, a humanized anti-VEGF antibody in vitro. Angiogenesis 2020;7:335-45.

54. Liu X, Liu C, Liu G, Luo W, Xia N. COVID-19: progress in diagnostics, therapy and vaccination. Theranostics 2020;10:7821-35.

55. Pardi N, Hogan MJ, Porter FW, Weissman D. mRNA vaccines-a new era in vaccinology. Nat Rev Drug Discovery 2018;17:261-79.

56. Tu YF, Chien CS, Yarmishyn AA, Lin YY, Luo YH, Lin YY, et al. A review of SARS-CoV-2 and the ongoing clinical trials. Int J MolSci 2020;21:2657.

57. Modjarrad K, Roberts CC, Mills KT, Castellano AR, Paolino K, Muthumani K,et al. Safety and immunogenicity of an antiMiddle East respiratory syndrome coronavirus DNA vaccine: a phase 1, open-label, single-arm, dose-escalation trial. Lancet Infect Dis 2019;19:1013-22.
58. Zhu FC, Li YH, Guan XH, Hou LH, Wang WJ, Li JX,et al. Safety, tolerability, and immunogenicity of a recombinant adenovirus type- 5 vectored COVID-19 vaccine: a dose-escalation, open-label, non-randomised, first-in-human trial. Lancet 2020;395:1845-54.

59. Vellozzi C, Burwen DR, Dobardzic A, Ball R, Walton K, Haber P. Safety of trivalent inactivated influenza vaccines in adults: background for pandemic influenza vaccine safety monitoring. Vaccine 2009;27:2114-20.

60. Rogliani P, Calzetta L, Coppola A, Cavalli F, Ora J,Puxeddu E, et al.Optimizing drug delivery in COPD: the role of inhaler devices. Respir Med2017;124:6-14.

61. Ratnam DV, Ankola DD, Bhardwaj V, Sahana DK, Kumar MNVR. Role of antioxidants in prophylaxis and therapy, a pharmaceutical perspective. J Controlled Release 2006;113:108-207.

62. Khalil MM, Alam MM, Arefin MK, Chowdhury MR, Huq MR, Chowdhury JA, et al.Role of personal protective measures in prevention of COVID-19 spread among physicians in bangladesh: a multicenter cross-sectional comparative study. SN ComprClin Med 2020;28:1-7.

63. Kamalasanan K, Biomimetric conjoining pathways for COVID19 drug discovery nanomedicine drug discovery and medical devices: prophylactic medicines as alternative for vaccines. Trends BiomaterArtif Organs 2020;34:73-4

64. Kucharski AJ, Klepac P, Conlan AJK, Kissler SM, Tang ML, Fry H, et al. CMMID COVID-19 working group. Effectiveness of isolation, testing, contact tracing, and physical distancing on reducing transmission of SARS-CoV-2 in different settings: a mathematical modelling study. Lancet Infect Dis 2020;20:1151-60.

65. Gogna KA, Tay H, Tan BS. Severe acute respiratory syndrome: 11 y later-a radiology perspective. Am JRoentgenol 2014;203:746-8. 